\title{
过渡金属催化有机钛试剂的偶联反应研究进展
}

\author{
黄辉李娟华刘昆明* 刘晋彪* \\ (江西理工大学冶金与化学工程学院 赣州 341000)
}

\begin{abstract}
摘要 有机钛试剂廉价低毒, 形态多样, 具有优异的化学、区域和立体选择性. 通过调整中心钛原子的配体可对有机钛 试剂的反应活性进行调控. 近年来, 有机钛试剂参与的偶联反应引起了化学家们的广泛关注. 从有机钛试剂类型出发, 就过渡金属催化有机钛试剂的偶联反应进行了简要综述.
\end{abstract}

关键词 过渡金属; 催化; 有机钛试剂; 偶联

\section{Recent Progress in Transition Metal-Catalyzed Coupling Reactions of Organotitanium Reagents}

\author{
Huang, Hui \\ Li, Juanhua \\ Liu, Kunming* \\ Liu, Jinbiao* \\ (School of Metallurgical and Chemical Engineering, Jiangxi University of Science and Technology, Ganzhou 341000)
}

\begin{abstract}
Organotitanium proves to be one of ideal organometallic candidates because of its low price, non-toxicity, diversified types, excellent chemo-, regio- and stereo-selectivities. The reactivity of organotitanium reagent could be easily controlled by ligands of central titanium atom. Recently, the coupling reactions of organotitanium reagent have attracted extensive attention. This review summerized recent progress in transiton metal-catalyzed coupling reactons of organotitanium reagents concerning their types.
\end{abstract}

Keywords transition metal; catalysis; organotitanium reagent; coupling

过渡金属催化的偶联反应是构建碳一碳键最常用和 最有效的方法之一. 在金属试剂参与的偶联反应(如金 属试剂与卤代烃或金属试剂间的氧化偶联反应)中, 经 典的有机金属试剂, 如格氏试剂 ${ }^{[1]}$ 、锂试剂 ${ }^{[2]}$ 因反应活性 较高, 常常会导致化学选择性较差或严重的自身偶联副 反应. 为此在偶联反应中, 人们常将格氏试剂和锂试剂 衍生为相应的锌试剂 ${ }^{[3]}$ 、铜试剂 ${ }^{[4]}$ 、硼试剂 ${ }^{[5]}$ 、锡试剂 ${ }^{[6]}$ 等. 尽管上述金属试剂已经广泛用于偶联反应中, 但拓 展更多高效、环保和来源易得的金属试剂还是具有重要 意义的.

钛是地壳中含量排名第 9 的元素, 来源广泛, 价格 低廉 ${ }^{[7]}$. 由于钛原子价态多, 配位数大, 配体类型丰富, 不同价态和配体的钛试剂反应性能各异 ${ }^{[8]}$. 如低价钛 (0、II、III 价) 的有机配合物可实现醛酮、酯、亚胺及羧
酸衍生物的还原偶联; 手性钛试剂可用于不对称环氧化 和加成; 钛酸酯及其衍生物可用作 Lewis 酸催化剂等. 这些方面已有一些论著和综述进行了总结 ${ }^{[9]}$. 近年来有 机钛试剂作为金属试剂参与偶联反应逐渐引起人们的 重视. 与其它金属试剂如锡试剂, 铜试剂等相比, 钛试 剂为无毒的环境友好型金属试剂. 与格氏试剂、锂试剂 相比, 钛试剂具有更高的化学选择性 ${ }^{[10]}$. 在有机金属试 剂的发展过程中, 一般采用两种途径来提高选择性和改 善反应性能: 利用不同的金属元素以 $\mathrm{C}-\mathrm{M}$ 键方式形成 的金属试剂如格氏试剂、锌试剂、嗍试剂等; 由经典的 格氏试剂、锂试剂与 Lewis 酸络合形成的 ate 络合物. 因 此, 本文将就过渡金属催化下具有 $\mathrm{C}$ - $\mathrm{Ti}$ 键的有机钣试 剂和 ate 络合物型有机钣试剂参与的偶联反应进行简要 的论述.

\footnotetext{
* Corresponding authors. E-mail: liukunminglkm@sina.com; liujbgood@hotmail.com Received October 29, 2018; revised December 19, 2018; published online January 9, 2019

Project supported by the National Natural Science Foundation of China (Nos. 21762018, 21772067), the Science and Technology Project Founded by the Education Department of Jiangxi Province (No. GJJ160668), the Program of Qingjiang Excellent Young Talents, Jiangxi University of Science and Technology, the Innovation and Entrepreneurship Training Program (No. XZG-16-08-12) and the Doctoral Scientific Research Foundation of Jiangxi University of Science and Technology.

国家自然科学基金(Nos. 21762018、21772067)、江西省教育厅科技项目(No. GJJ160668)、江西理工大学清江青年英才计划项目、江西理工大学大学 生创新创业训练计划项目(No. XZG-16-08-12)及江西理工大学博士启动经费资助项目.
} 


\section{1 具有 C一 $\mathrm{Ti}$ 键的有机钛试剂的偶联反应}

根据 $\mathrm{C}$ - $\mathrm{Ti}$ 键的类型，该类钛试剂可分为三种: (1) 具有 $\mathrm{C}-\mathrm{Ti} \sigma$ 键的有机钠化合物; (2)具有 $\mathrm{C}-\mathrm{Ti} \pi$ 键的有 机钛化合物; (3) 同时具有 $\mathrm{C}-\mathrm{Ti} \sigma$ 键和 $\mathrm{C}-\mathrm{Ti} \pi$ 键的有机 钛化合物. 迄今为止, 人们的研究主要集中在过渡金属 催化下第一种钛试剂参与的偶联反应, 后两种钛试剂的 偶联报道较少.

\section{1 具有 $\mathrm{C}-\mathrm{Ti} \sigma$ 键的有机钛试剂的偶联反应}

具有 $\mathrm{C}-\mathrm{Ti} \sigma$ 键的有机钛试剂, 如 $\left\{[\mathrm{R}(\mathrm{Ar})]_{n} \mathrm{TiX}_{4-n}\right.$, $\mathrm{X}=\mathrm{Cl}, \mathrm{Br}, \mathrm{OR}, \mathrm{NR}_{2}$, etc. $\}$, 其中的烃基与钛原子以 $\sigma$ 键 相连. 这类钛试剂一般由有机镁试剂或锂试剂与钛化合 物置换而来, 通过调节 $\mathrm{X}$ 的种类和数目, 种类丰富、性 能各异的有机钛试剂均可制备 ${ }^{[7]}$ (Eq. 1).

$$
\mathrm{R}(\mathrm{Ar}) \mathrm{M}+\mathrm{TiX}_{4} \longrightarrow[\mathrm{R}(\mathrm{Ar})]_{n} \mathrm{TiX}_{4-n}
$$

$\mathrm{M}=\mathrm{Li}, \mathrm{MgX}$, etc

$\mathrm{X}=\mathrm{Cl}, \mathrm{Br}, \mathrm{OR}, \mathrm{NR}_{2}$, etc. $\quad n=1,2$

自 1952 年 Herman 和 Nelson ${ }^{[11]}$ 制备出第一例有机 钛试剂 $\mathrm{PhTi}(\mathrm{OiPr})_{3}$ 以来，该类有机钛试剂多用于对羰基 化合物的选择性加成. 直到 1984 年, Tolstikov 等 ${ }^{[12]}$ 报道 了首例有机钛试剂的偶联反应. 在钯催化下, 芳基钛酸 三乙酯与烯丙基溴反应以较高收率获得偶联产物. 遗憾 的是, 反应的区域选择性很差, 得到两种位置异构体的 混合物. 随后, 作者 ${ }^{[13]}$ 研究了钛试剂配体结构对反应的 影响. 发现当 $\mathrm{X}$ 为 OEt 时, 反应获得最佳的选择性 (Table 1, Entry 1), 尽管当 $\mathrm{X}$ 为 $\mathrm{O}^{t} \mathrm{Bu}$ 时也能达到相近的 选择性, 但收率很低(Table 1, Entry 3). 采用其它配体如 $\mathrm{OPh}$ 和 $\mathrm{NEt}_{2}$ 等, 因存在聚合导致收率和选择性均较差 (Table 1, Entries 4 \& 5). 作者同时还系统地研究了催化 剂和溶剂种类对反应的影响, 最终实现了钯催化烯丙基 卤代烃与有机钛试剂的选择性偶联, 并在此基础上将亲 电试剂拓展至烯丙基酯和烯丙基磺酸酯 ${ }^{[14]}$. 尽管 Tolstikov 等的研究存在一定的局限性, 如亲电部分只限 于烯丙基亲电试剂，反应中未体现出官能团耐受性等， 但已充分说明在过渡金属催化的偶联反应中, 有机钛试 剂可作为亲核部分参与偶联, 并且具有自己独特的优 点，即通过调整钛试剂配体种类来调控反应的选择性.

由于多数钛试剂不是固体, 难以方便地分离、纯化 和保存. 因此在这一时期, 人们多采用原位制备有机钛 试剂直接用于反应. 同时由于钛试剂配体的复杂性, 加 之早期表征手段的限制，人们对有机钛试剂的结构缺乏 深入的了解. 上述原因导致过渡金属催化有机钛试剂偶 联反应的研究在上世纪末陷入低谷. 本世纪初, 随着高 选择性偶联反应的兴起，通过金属试剂精确调控反应
表 1 钯催化有机钛试剂与烯丙基溴代烃的偶联反应 Table 1 Palladium-catalyzed coupling of organotitanium reagents with allyl bromides

\begin{tabular}{|c|c|c|c|c|}
\hline & & $20 \circ C$ & I & II \\
\hline \multirow{2}{*}{ Entry } & \multirow{2}{*}{$\mathrm{X}$ in $\mathrm{PhTiX}_{3}$} & \multirow{2}{*}{ Time/h } & \multicolumn{2}{|c|}{ Yield/\% } \\
\hline & & & I & II \\
\hline 1 & OEt & 1 & 80 & 18 \\
\hline 2 & OiPr & 1 & 77 & 22 \\
\hline 3 & $\mathrm{OtBu}$ & 2 & 49 & 11 \\
\hline 4 & $\mathrm{OPh}$ & 12 & 60 & 25 \\
\hline 5 & $\mathrm{NEt}_{2}$ & 12 & 48 & 17 \\
\hline
\end{tabular}

活性和选择性成为实现该类反应的重要手段. 由于有机 钛试剂配体丰富、易于调控的优点，在对羰基亲核加成 反应中显示出独特选择性 ${ }^{[15]}$, 再一次引起了人们的关 注.

2002 年, Hayashi 等 ${ }^{[16]}$ 报道了钯、镍催化有机钛试 剂与三氟甲磺酸萗酚酯的偶联反应. 反应中几种钛试剂 如 $\operatorname{MeTi}\left(\mathrm{O}^{i} \mathrm{Pr}\right)_{3} 、 \operatorname{PhTi}\left(\mathrm{O}^{i} \mathrm{Pr}\right)_{3}$ 等具有较高的热稳定性，在 THF 回流温度下能顺利地实现偶联. 值得注意的是, 在 该催化反应中, 不同形态有机钛化合物均能高效完成偶 联反应，其中 0.6 equiv. $\mathrm{Ph}_{2} \mathrm{Ti}\left(\mathrm{O}^{i} \mathrm{Pr}\right)_{2}$ 的偶联收率与 1.2 equiv. $\operatorname{PhTi}\left(\mathrm{O}^{i} \mathrm{Pr}\right)_{3}$ 的偶联收率相当, 说明前者所含两个 苯基均参与了偶联，由此可见钛试剂偶联反应具有很高 的原子经济性(Table 2, Entries $2 \& 3$ ).

表 2 钯催化有机钣试剂与芳基磺酸酯的偶联反应 Table 2 Palladium-catalyzed coupling of organotitanium reagents with aryl triflates

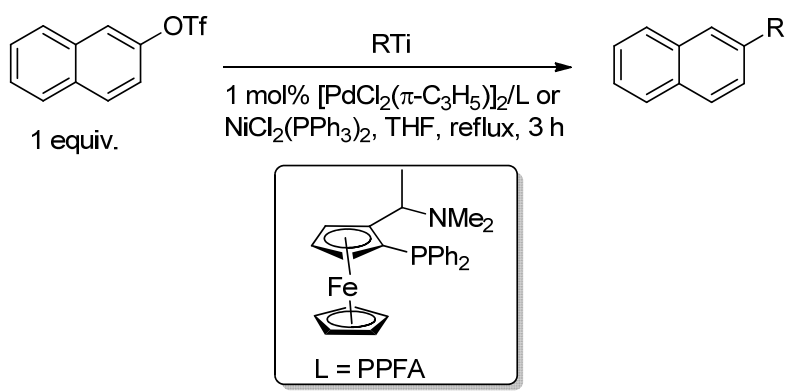

\begin{tabular}{cccc}
\hline Entry & $\mathrm{RTi}($ equiv. $)$ & Time $/ \mathrm{h}$ & Yield $/ \%$ \\
\hline 1 & $\mathrm{MeTi}\left(\mathrm{O}^{i} \mathrm{Pr}\right)_{3}(1.5)$ & 3 & 96 \\
2 & $\mathrm{PhTi}\left(\mathrm{O}^{i} \mathrm{Pr}\right)_{3}(1.2)$ & 3 & 98 \\
3 & $\mathrm{Ph}_{2} \mathrm{Ti}^{i}\left(\mathrm{O}^{i}\right)_{2}(0.6)$ & 3 & 98 \\
\hline
\end{tabular}

2007 年, Knochel 等 ${ }^{[17]}$ 采用镍-卡宾催化, 室温下实 现了芳基钛试剂和卤代芳烃的偶联反应(Scheme 1). 由 于反应无需加热，因此钛试剂的配体不必使用热稳定性 高的 $\mathrm{O}^{i} \mathrm{Pr}$ 而选用了位阻更小的 OEt，从而使钛试剂制备 时间更短，收率更高. 该反应不仅适用于芳基钛试剂， 
$\mathrm{N}$-甲基吡咯和吲哚等杂环钛试剂同样能顺利地实施偶 联. 在卤代烃底物中, 酮羰基、缩醛、磺酰胺基、酯基 等敏感基团均能耐受该反应条件, 显示出有机钛试剂优 异的化学选择性.
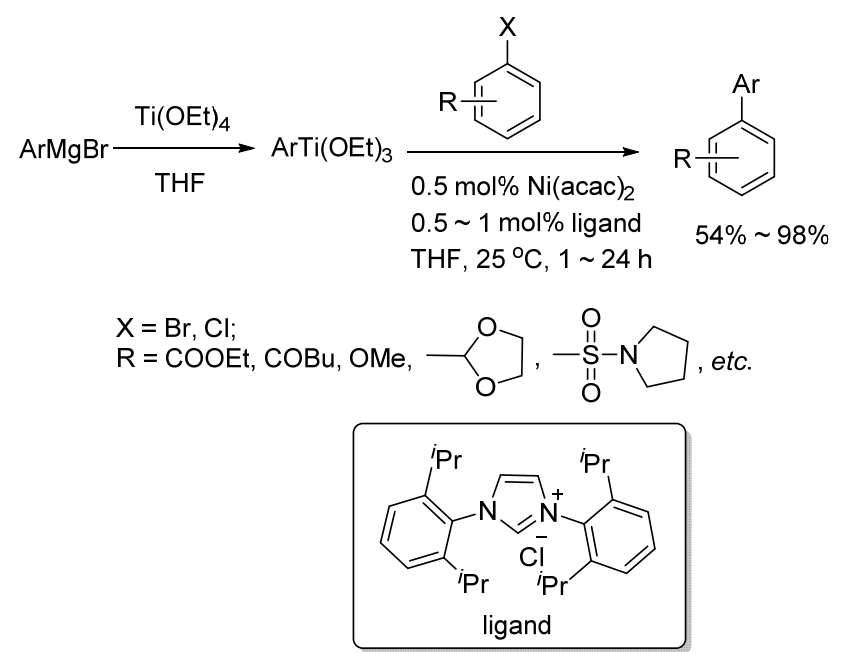

图式 1 镍催化芳基钛试剂和卤代芳烃的偶联反应

Scheme 1 Nickel-catalyzed coupling of aryl titanium reagents with aryl halides.

这两例反应表明, 钛试剂参与的偶联反应具有高 效、高选择性的特点. 美中不足的是, 两者的普适性尚 有待发掘, 如 Hayashi 的反应中亲电试剂局限于三氟甲 磺酸䒺酚酯, 仅尝试了两例溴代芳烃与甲基钛试剂的偶 联反应; Knochel 的反应中钛试剂配体单一, 仅限于钛酸 乙酯. 2009 年, Kwong 等 ${ }^{[18]}$ 进一步拓展了钛试剂参与的 偶联反应. 在两种结构复杂的氮磷配体 L1 和 $\mathbf{L 2}$ (Scheme 2)作用下, 氯代和溴代芳烃均能与芳基钛试剂 实现高化学选择性的芳基化反应, 偶联产率最高达 99\%. 该反应具有很强的底物适用性和官能团耐受性, 含有酯基、氰基等敏感官能团或具有较大空间位阻的卤 代烃均能顺利实施偶联. 对于芳基钛试剂而言, 无论取 代基为吸电子基或推电子基, 偶联反应都具有很高的收 率. 值得一提的是, 作者还同时尝试了首例钯催化芳基 钛试剂与磺酰氯的偶联反应，以中等的收率得到芳基 砜, 为过渡金属催化芳基钛试剂的 $\mathrm{C}-\mathrm{S}$ 键偶联开启了 一条新途径(Scheme 2).

同一时期, Gau 课题组 ${ }^{[19]}$ 在拓展了钛试剂参与的偶 联反应时, 对芳基钛试剂的分离方法和结构进行了研究 (Scheme 3). 作者首先将芳基格氏试剂和 $\mathrm{ClTi}\left(\mathrm{O}^{i} \mathrm{Pr}\right)_{3}$ 原 位反应生成相应芳基钛试剂, 随后在正己烷中重结晶分 离得到了它们的晶体, 并通过变温核磁、单晶衍射等手 段对其结构进行了表征，结果表明所制备的芳基钛试剂 是以 $\left[\operatorname{ArTi}\left(\mathrm{O}^{i} \mathrm{Pr}\right)_{2}\left(\mu-\mathrm{O}^{i} \mathrm{Pr}\right)\right]_{2}$ 这种二聚体的结构存在. 这一
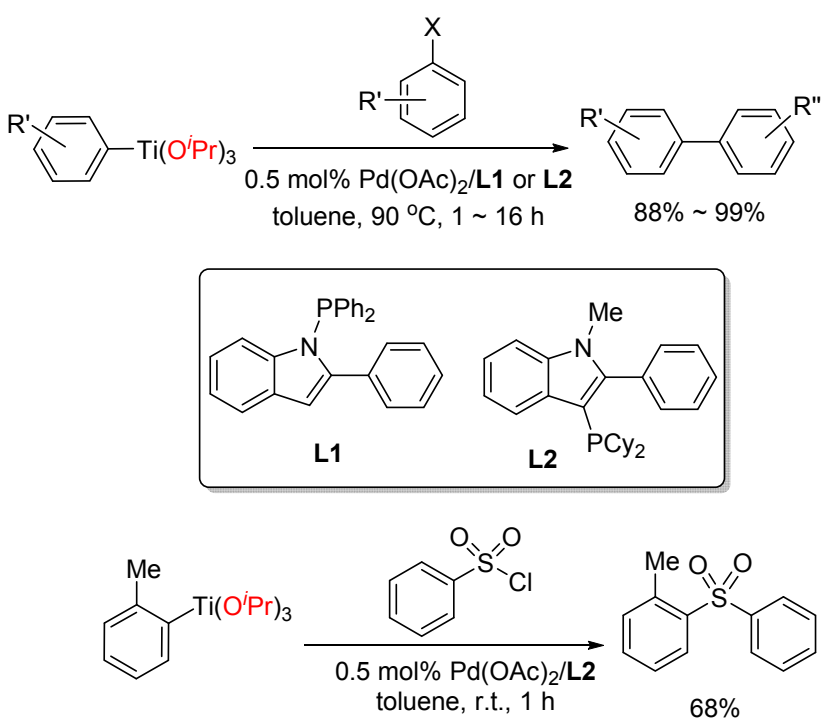

图式 2 钯催化芳基钛试剂与卤代芳烃、苯磺酰氯的偶联反应 Scheme 2 Palladium-catalyzed coupling of aryl titanium reagents with aryl halides and benzenesulfonyl chloride.

工作为揭示有机钛试剂精细结构、拓展有机钛试剂类 型、研究反应机理奠定了基础. 在此基础上, Gau 等进一 步拓展了钛试剂参与的偶联反应范围, 利用芳基钛试剂 实现了有机底物的芳基化反应和芐基化反应. 反应同样 具有优异的官能团耐受性，含有氰基、酯基、硝基等官 能团的卤代芳烃或茮卤均能顺利的实现偶联.

$$
\mathrm{TiCl}_{4}+3 \mathrm{Ti}\left(\mathrm{O}^{\prime} \mathrm{Pr}\right)_{4} \underset{\substack{0^{\circ} \mathrm{C} \sim \text { r.t. } \\ 30 \text { min }}}{\stackrel{\mathrm{THF}}{\longrightarrow}} \mathrm{ClTi}\left(\mathrm{O}^{i} \mathrm{Pr}\right)_{3} \underset{\text { 年MgBr/THF }}{\stackrel{0^{\circ} \mathrm{C} \sim \text { r.t. }}{3}}
$$$$
\left[\operatorname{ArTi}\left(\mathrm{O}^{\prime} \mathrm{Pr}\right)_{2}\left(\mu-\mathrm{O}^{\prime} \mathrm{Pr}\right)\right]_{2} \equiv 2 \operatorname{ArTi}\left(\mathrm{O}^{\prime} \mathrm{Pr}\right)_{3}
$$

$\mathrm{Ar}=\mathrm{Ph}, 2-\mathrm{MeC}_{6} \mathrm{H}_{4}, 4-\mathrm{MeC}_{6} \mathrm{H}_{4}, 4-\mathrm{ClC}_{6} \mathrm{H}_{4}, 4-\mathrm{Me}_{3} \mathrm{SiC}_{6} \mathrm{H}_{4}$, $4-\mathrm{CF}_{3} \mathrm{C}_{6} \mathrm{H}_{4}, 3,5-\mathrm{Me}_{2} \mathrm{C}_{6} \mathrm{H}_{3}$
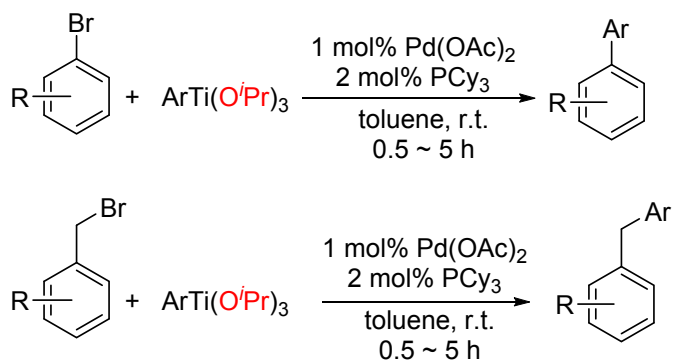

$\mathrm{R}=\mathrm{MeO}, \mathrm{CN}, \mathrm{COOMe}, \mathrm{NO}_{2}, \mathrm{Cl}$, etc.

图式 3 钯催化芳基钛试剂的芳基化和苄基化反应 Scheme 3 Palladium-catalyzed arylation and benzylation reactions of aryl titanium reagents.

2012 年, 该课题组 ${ }^{[20]}$ 采用类似的方法分离提纯出 苄基钛试剂，并成功应用于钯催化的芳基化反应 (Scheme 4). 与芳基钛试剂相比，苄基钛试剂熔点很低， 需在 $-20{ }^{\circ} \mathrm{C}$ 下才能重结晶. 反应同样采用简单的 
$\mathrm{Pd}(\mathrm{OAc})_{2}$ 和 $\mathrm{PCy}_{3}$ 催化体系, 普通的溴代芳烃在 $1 \mathrm{~h}$ 内即 能顺利地完成偶联得到二芳基甲烷衍生物. 对于空间位 阻较大或含有吸电子取代基的溴代芳烃、溴代杂芳烃等, 通过延长反应时间及升温等手段同样能获得不错的收 率. 作者提出可能的机理, 首先 $\mathrm{Pd}(\mathrm{OAc})_{2}$ 上的两个醋酸 根被钛试剂中的茮基取代, 随即发生还原消除得到 $\mathrm{ArCH}_{2} \mathrm{CH}_{2} \mathrm{Ar}$, 所形成的 $\mathrm{Pd}(0)$ 与 $\mathrm{PCy}_{3}$ 络合形成 $\mathrm{Pd}\left(\mathrm{PCy}_{3}\right)_{2}(\mathbf{I})$, 后者随即与溴代芳烃或杂芳烃进行氧化 加成得到 $\mathrm{Pd}(\mathrm{II})$ 的中间体 $\left(\mathrm{Cy}_{3} \mathrm{P}\right)_{2} \mathrm{Pd}(\mathrm{Ar} / \mathrm{Het} \mathrm{Ar}) \mathrm{Br}$ (II), 继 而与茮基钛试剂进行转金属化生成中间体 III，最后通 过还原消除得到偶联产物, 并重新生成零价钯开始下一 次循环。
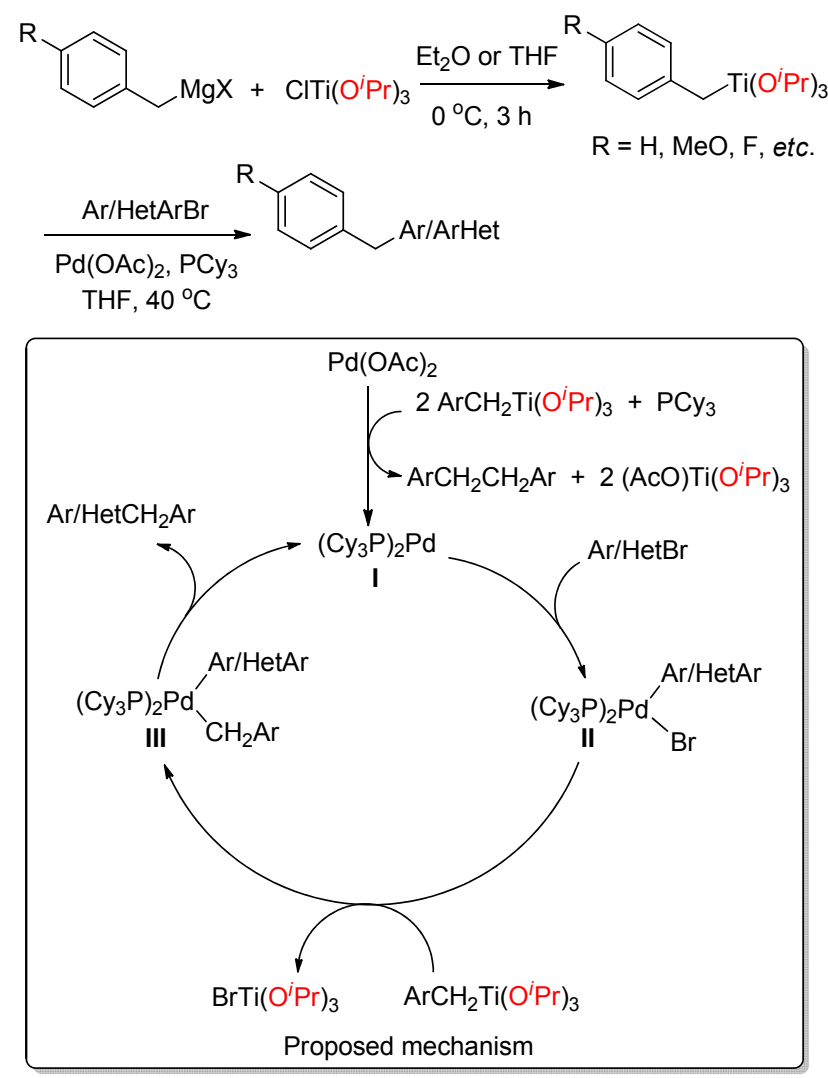

图式 4 钯催化苄基钛试剂的偶联反应

Scheme 4 Palladium-catalyzed coupling of benzyl titanium reagents.

2014 年, 该课题组 ${ }^{[21]}$ 进一步研究了炔丙基卤代烃 和有机钛试剂的偶联. 作为一种多反应位点的试剂, 炔 丙基卤代烃与金属试剂反应存在两种途径: 历经 $\mathrm{S}_{\mathrm{N}} 2$ 过 程得到联烯或历经 $\mathrm{S}_{\mathrm{N}} 2$ '过程得到炔烃(Scheme 5). 在两 种途径间存在竞争，常见的金属试剂如格氏试剂、锂试 剂等由于活性更高, 很难获得高选择性的反应. 借助于 有机钛试剂活性适中的特点, Gau 等通过篮选催化体系, 实现了炔丙基卤代烃选择性合成炔烃及联烯的偶联反 应. 反应的选择性与催化剂及反应底物结构有关：当采
用 $\mathrm{NiCl}_{2} / \mathrm{PCy}_{3}$ 催化炔丙基溴或采用 $\mathrm{Ni}\left(\mathrm{PPh}_{3}\right)_{2} \mathrm{Cl}_{2}$ 催化位 阻较小的末端取代炔丙基溴反应时，主要以 $\mathrm{S}_{\mathrm{N}} 2$ 途径得 到联烯; 而采用 $\mathrm{Ni}\left(\mathrm{PPh}_{3}\right)_{2} \mathrm{Cl}_{2}$ 催化位阻大的末端取代炔 丙基氯反应则以 $\mathrm{S}_{\mathrm{N}} 2^{\prime}$ 途径得到炔烃. 对于这种差异, 作 者提出了可能的机理: 首先 $\mathrm{NiCl}_{2}$ 在 $\operatorname{ArTi}\left(\mathrm{O}^{i} \mathrm{Pr}\right)_{3}$ 作用下 发生还原消除，与 $\mathrm{PR}_{3}^{\prime}$ 形成零价镍络合物 $\mathrm{Ni}\left(\mathrm{PR}_{3}^{\prime}\right)_{2}(\mathbf{1})$, 随后 1 与炔丙基卤代烃进行氧化加成形成 $\mathrm{Ni}$ (II)配合物 2. 此时, 2 可直接经历转金属化生成相应的钣配合物 $\mathbf{3}$, 也可先异构化生成 $\mathbf{4}$, 再历经转金属化生成配合物 $\mathbf{5}$. 中 间体 3 或 5 最后通过还原消除得到炔烃 7 或联烯 6 . 当 $\mathrm{NiCl}_{2} / \mathrm{PCy}_{3}$ 催化炔丙基溴、 $\mathrm{Ni}\left(\mathrm{PPh}_{3}\right)_{2} \mathrm{Cl}_{2}$ 催化位阻小的取 代炔丙基澳时，所生成的中间体 2 不稳定，容易发生异 构化生成 4, 因此产物主要为联烯, 而 $\mathrm{Ni}\left(\mathrm{PPh}_{3}\right)_{2} \mathrm{Cl}_{2}$ 催化 位阻大的取代炔丙基氯时，中间体 2 较稳定，因此产物 主要为炔.

\section{2 具有 C- Ti m 键的有机钛试剂的偶联反应}

除了形成 $\mathrm{C}-\mathrm{Ti} \sigma$ 键, 钛原子还能和 $\mathrm{C}=\mathrm{C} 、 \mathrm{C} \equiv \mathrm{C}$ 等不饱和键通过 $\pi$ 键络合, 形成钛一烯或钛一炔络合物. 其中，炔基金属络合物作为 1,2-双碳负离子合成子是引 入 $\mathrm{C}=\mathrm{C}$ 键的一种有效手段 ${ }^{[22]}$. 但传统的钛-炔络合物 如 $\left(\eta^{2}\right.$-alkyne $) \mathrm{Ti}(\mathrm{OiPr})_{2}$ 热稳定性差, 只能在 $-30{ }^{\circ} \mathrm{C}$ 以下 使用 ${ }^{[23]}$ ，限制了其在偶联反应中的应用. 2003 年, Tsuji 等 ${ }^{[24]}$ 报道了首例镍催化钛-炔络合物与碘代芳烃的偶联 反应(Scheme 6). 作者在-78 ${ }^{\circ} \mathrm{C}$ 下将 2 equiv. BuLi 缓慢 滴加至 $\mathrm{Ti}\left(\mathrm{O}^{i} \mathrm{Pr}\right)_{4}$ 和炔的混合物中, 所生成的络合物在 $50{ }^{\circ} \mathrm{C}$ 左右仍十分稳定. 在 $\mathrm{Ni}(\mathrm{COD})_{2}$ 催化下，该络合物 与碘代芳烃偶联生成芳基取代的烯烃.

此外，也有几例无过渡金属催化钛一炔络合物参与 的偶联反应. 2014 年, Liu 等 ${ }^{[25]}$ 以钛一炔络合物为媒介, 实现了 1,3-丁二炔与 $\alpha$-氰基亚胺的偶联反应(Scheme 7). 首先，在 $\mathrm{BuLi}$ 作用下, $\mathrm{Ti}\left(\mathrm{O}^{i} \mathrm{Pr}\right)_{4}$ 与 1,3 -丁二炔 $(\mathbf{1})$ 生成铁炔络合物 $2, \alpha$-氰基亚胺 3 中的 $\mathrm{C} \equiv \mathrm{N}$ 通过 $\mathrm{S}_{\mathrm{E}} 2^{\prime}$ 进攻 $\mathbf{2}$ 中 位阻较小的炔基碳形成氮杂累积二烯烃-钣环状络合物 4, 后者异构化为氮杂环戊二烯铁络合物 $\mathbf{5}$, 并通过水解 生成双亚胺化合物 6. 随后在 Lewis 酸作用下经过中间 体 7 9, 完成亚胺型氮杂 Nazarov 反应, 得到多取代吡 咯化合物 $\mathbf{1 0 .}$

同一时期, Six 等 ${ }^{[26]}$ 以钛-炔络合物为媒介, 实现了 芳基炔的 $[2+2+2]$ 环三聚化反应(Scheme 8 ). 内炔 1 首 先在 $\mathrm{BuLi}$ 和 $\mathrm{Ti}\left(\mathrm{O}^{i} \mathrm{Pr}\right)_{4}$ 作用下生成钛-炔络合物 $\mathbf{2 , 2}$ 与一 分子炔烃 3 反应形成二异丙氧基环戊二烯钛络合物 4 和 $\mathbf{5}$, 再与另一分子炔烃 3 进行环三聚化反应得到多取代 芳烃异构体 $6 \sim 8$. 由上述几例反应可见，尽管目前钛炔络合物参与的偶联反应不多, 但为这类络合物作为碳 负离子源在有机合成中的应用提供了一条新途径. 

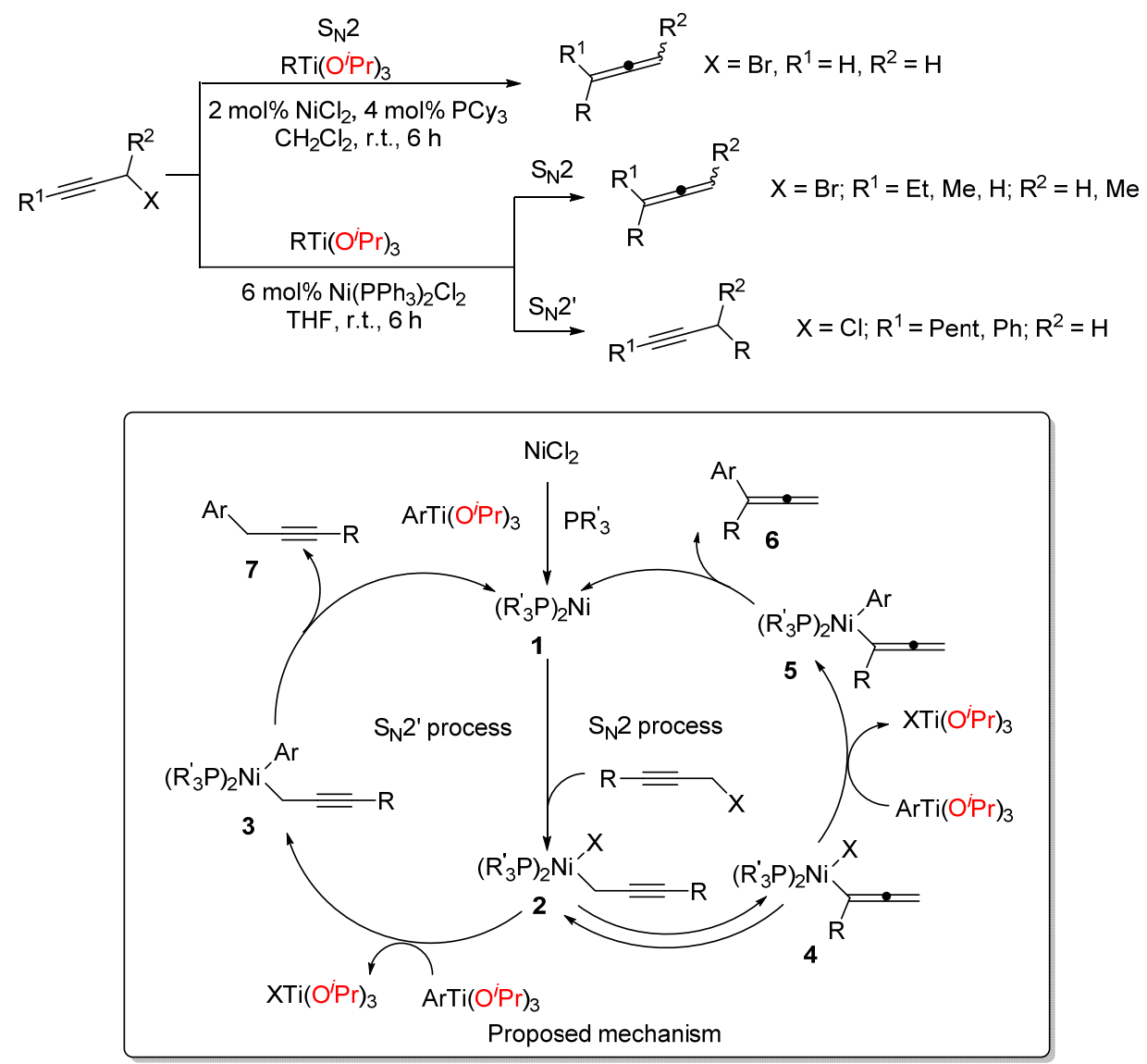

图式 5 镍催化炔丙基卤代烃和有机钛试剂的偶联反应

Scheme 5 Nickle-catalyzed cross-coupling reactions of propargyl halides with organo titanium reagents

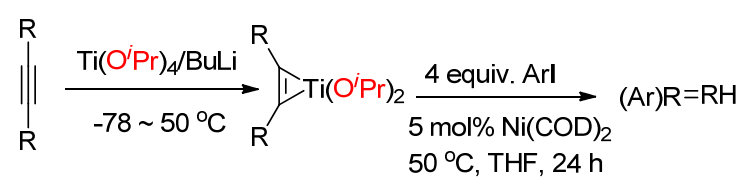

图式 6 镍催化钛一炔络合物与碘代芳烃的偶联反应 Scheme 6 Nickel-catalyzed coupling of Ti(II)-alkyne complexes with aryl iodides

\section{2 ate 络合物型钛试剂的偶联反应}

酸根型配合物(ate-complex)最早由 Wittig ${ }^{[27]}$ 于 1958 年引入, 指由 Lewis 酸和特定的碱生成的中心原子价态 升高的盐. 由格氏试剂、锂试剂与 $\mathrm{Zn} 、 \mathrm{~B} 、 \mathrm{Cu}$ 等 Lewis 酸络合形成的酸根型配合物, 展现出与经典有机金属试 剂明显不同的反应性能. 如铁催化的 Suzuki 反应中, 转 金属过程在催化循环中起决定作用. 而传统的硣试剂如 有机嗍酸或硼酸酯上的亲核基团都没有足够的活性转 移到铁催化剂上 ${ }^{[28]} .2010$ 年以来, Nakamura 等 ${ }^{[29]}$ 采用锂 试剂、格氏试剂与喼酸酯形成的 ate 络合物, 具有更高 的亲核性, 在铁催化下顺利实现了与脂肪族卤代烃的 Suzuki 偶联.
以钛化合物作为 Lewis 酸, 有机镁试剂或锂试剂作 为 Lewis 碱, 络合形成 ate 络合物型钛试剂(Eq. 2). 这类 钛试剂制备方便, 只需在一定条件下将有机镁试剂或锂 试剂与相应的钛化合物混合即可获得. 与具有 $\mathrm{C}-\mathrm{Ti}$ 键 的有机钛试剂相比, ate 络合物型钛试剂在一些反应实例 中表现出独特的性质. 如 Harada 等 ${ }^{[30]}$ 将有机镁试剂或 锂试剂形成的 ate 络合物型钛试剂用于醛、酮类化合物 的不对称反应，获得高对映选择性的加成产物. 另外, 含氟格氏试剂十分不稳定，容易发生 $\alpha$-或 $\beta$-氟消除反 应，含氟格氏试剂与 $\mathrm{Ti}\left(\mathrm{O}^{i} \mathrm{Pr}\right)_{4}$ 形成 ate 络合物型钛试剂 后能明显抑制这种现象 ${ }^{[31]}$. 此外, 此类钛试剂类型丰 富，通过改变化合物配体 $\mathrm{Y}$, 即可调整金属试剂的反应 行为.

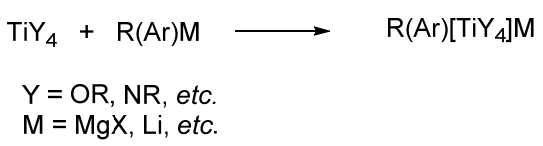

然而，长期以来，过渡金属催化 ate 络合物型钛试 剂参与的偶联反应报道很少, 如 Hayashi 等 ${ }^{[16]}$ 在研究具 有 $\mathrm{C}$ - $\mathrm{Ti}$ 键有机钛试剂的偶联反应时(Table 2), 也尝试 


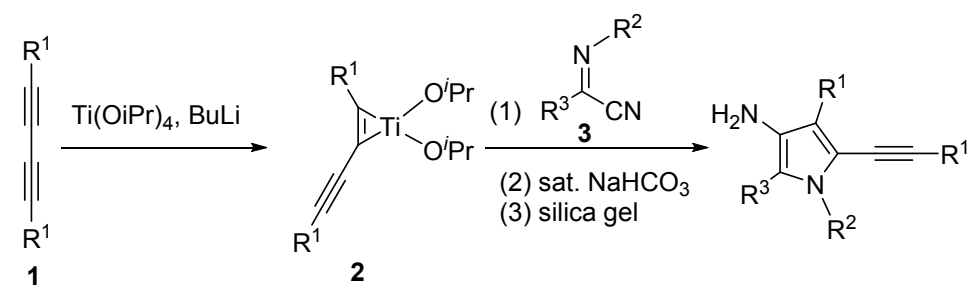

$\mathrm{R}^{1}=$ silyl, aryl, alkyl; $\mathrm{R}^{2}, \mathrm{R}^{3}=$ aryl or alkyl

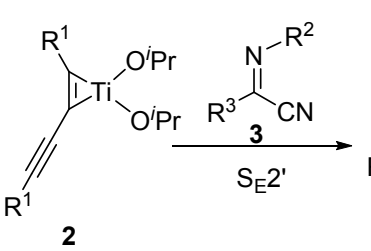

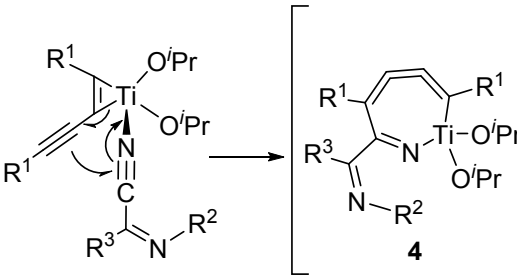

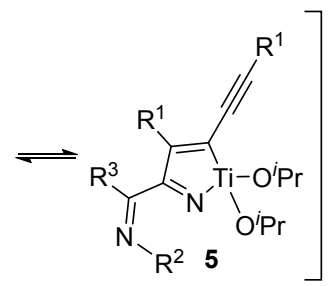
sat. $\mathrm{NaHCO}_{3}$

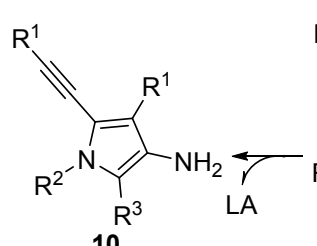

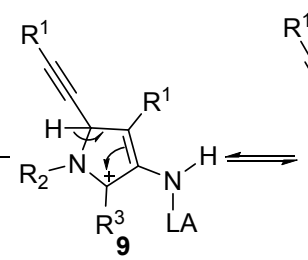

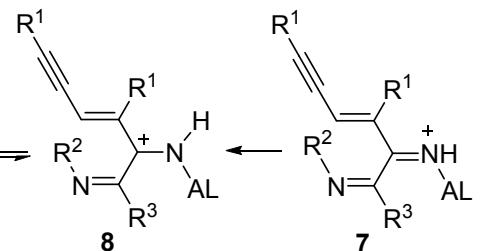<smiles>C[13CH3]</smiles><smiles>[R]C#CC=C([R])C(=N)N=[V]</smiles>

imino aza-nazarov reaction

Proposed mechanism

图式 7 钛-炔络合物与 $\alpha$-氰基亚胺的偶联反应

Scheme 7 Cross-coupling reaction of Ti(II)-alkyne complexes with $\alpha$-iminonitriles

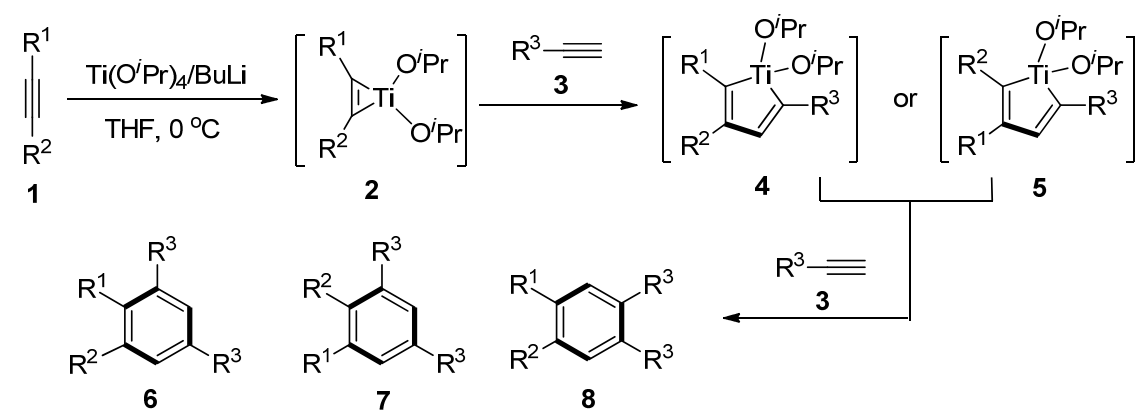

图式 8 钛一炔络合物的 $[2+2+2]$ 环三聚反应

Scheme $8 \quad[2+2+2]$ cyclotrimerisation reaction of Ti(II)-alkyne complexes

了一例 ate 络合物型钛试剂的偶联, 即采用 $\mathrm{Ph}[\mathrm{Ti}$ $\left.\left(\mathrm{O}^{i} \mathrm{Pr}\right)_{4}\right] \mathrm{Li}$ 实现了 2-䒺基三氟甲磺酸酯的苯基化反应( Eq. 3). Nakamura 等 ${ }^{[32]}$ 在铜催化烯丙基氯及磷酸酯的烷基化 反应中发现, ate 络合物型钛试剂不仅比相应的有机钛试 剂活性高, 还能选择性地发生取代反应而不发生共轭加 成(Scheme 9).

近年来，过渡金属催化下多种金属间的协同效应引 起了人们的高度关注 ${ }^{[33]}$. 经典的 ate 络合物如铜锂试剂、 镁锂试剂中两种金属间存在明显的协同效应, 在化学、 区域和立体选择性上表现出独特的性质 ${ }^{[34]}$. 与主族元

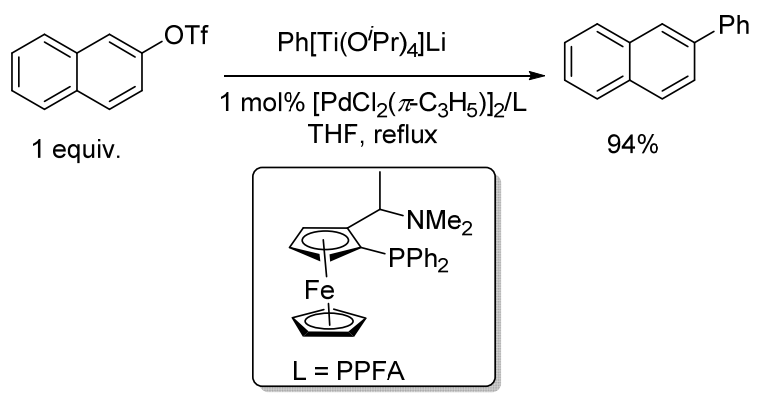

素相比, 钛原子半径大, 配位数大, 配体种类多样, 络 合作用也因钛未充满的 $\mathrm{d}$ 轨道而方式多、强度大 ${ }^{[7]}$. 因 


$$
\begin{aligned}
& \curvearrowright \mathrm{Cl}+\mathrm{RTi} \stackrel{\text { Cat. } \mathrm{Cu} \cdot 2 \mathrm{LiCl}}{\longrightarrow} \\
& \mathrm{RTi}=\mathrm{BuTi}\left(\mathrm{O}^{i} \mathrm{Pr}\right)_{3} \quad 66 \% \text { yield } \\
& \mathrm{RTi}=\mathrm{Bu}_{2} \mathrm{Ti}\left(\mathrm{O}^{i} \mathrm{Pr}\right)_{3} \mathrm{Li} 88 \% \text { yield }
\end{aligned}
$$
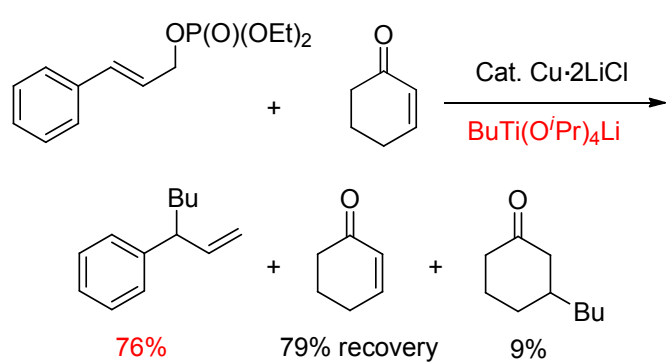

图式 9 Ate-complex 型钛试剂参与的烯丙基化反应

Scheme 9 Reactions of ate-complex titanium reagents

此，钣试剂与过渡金属之间，有望通过双金属协同实现 高效、高选择性地催化偶联反应. 2013 年, 我们课题 组 ${ }^{[35]}$ 报道了首例钴钛协同催化芳基金属试剂与卤代芳 烃的偶联反应(Scheme 10). 首先在 $\mathrm{Ti}(\mathrm{OEt})_{4}$ 中滴入芳基 格氏试剂形成 ate-络合物, 再通过与 4-溴二苯甲酮的偶 联反应为模型, 考察了不同钴盐、配体、溶剂等对交叉 偶联反应的影响，获得最佳条件为：以 $7.5 \mathrm{~mol} \% \mathrm{CoCl}_{2}$ 、 $15 \mathrm{~mol} \% \mathrm{PBu}_{3} 、 \mathrm{THF}$ 为溶剂. 反应具有优异的化学选择 性，不仅可以耐受诸如酮羰基、酯基、氰基、酰胺基、 磺酰胺基、磺酸酯基等对格氏试剂或锂试剂十分敏感的 基团, 而且还可以在不经保护的 $\mathrm{COOH}, \mathrm{OH}$ 等基团存在 下高效偶联. 除了卤代芳烃, 卤代含氮杂环在该催化体 系下同样能顺利地实现偶联. 值得一提的是, 通过考察 钛酸酯类型及比例的影响, 发现反应中的 ate 络合物不 需要等化学计量的格氏试剂与钛酸酯生成, 只需加入 $40 \mathrm{~mol} \% \mathrm{Ti}\left(\mathrm{OC}_{2} \mathrm{H}_{5}\right)_{4}$ (以 $\mathrm{ArM}$ 的量来计)即可起到 ate 络合 物的作用，因此该体系可视为钴钛协同催化体系.

此外, 在上述反应中还发现酮羰基能使邻位的卤原 子活化. 在此基础上, 我们 ${ }^{[36]}$ 对钴钛协同催化氟代芳烃 的偶联反应进行了研究. 与前例相比, 反应摒弃了有毒 的膦配体, 改用毒性较小的 DMPU 作配体. 当氟原子位 于氨基、羧基、酮羰基等邻位时, 受到很强的活化作用, 即使其它位置有澳或氯存在, 偶联反应也将选择性地发 生在邻位. 另外, 当反应温度升高至 $50{ }^{\circ} \mathrm{C}$, 未活化的 氟代芳烃也能顺利地实现偶联, 此时反应仍具有优异的 官能团耐受性. 尽管整个反应的历程还不清晰，但通过 实验认为, 钴钣双金属协同作用对于反应的选择性起到 至关重要的作用. 钴钛双金属络合物将协同促进 $\mathrm{C}-\mathrm{F}$ 键的断裂，完成氧化加成过程(Scheme 11).

与钴相比, 铁更为廉价环保, 是一种理想的催化剂. 然而，铁催化澳代和碘代芳烃与芳基金属试剂的 $\mathrm{C}\left(\mathrm{sp}^{2}\right)-\mathrm{C}\left(\mathrm{sp}^{2}\right)$ 偶联受到脱卤和金属试剂自身偶联副反
$\mathrm{Ar}$ 'X $+\mathrm{ArM}+\mathrm{Ti}(\mathrm{OEt})_{4} \underset{15 \mathrm{~mol}_{0} \mathrm{PBu}_{3} \text {, THF, r.t. }}{\stackrel{7.5 \mathrm{~mol}^{2} \mathrm{CoCl}_{2}}{\longrightarrow}} \mathrm{Ar} \mathrm{Ar}$

1 equiv. 1.4 equiv. 0.56 equiv.

$\mathrm{X}=\mathrm{Br}, \mathrm{Cl}$, etc. $\mathrm{M}=\mathrm{MgX}, \mathrm{Li}$, etc.
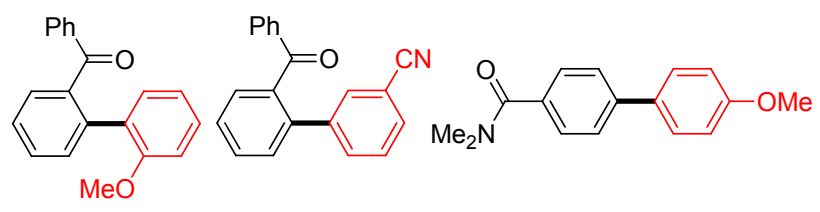

$98 \%$

$72 \%$

$81 \%$

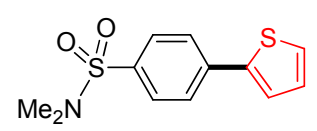

$81 \%$

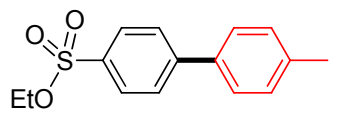

$87 \%$<smiles>O=C(O)c1cccc(P)c1</smiles>

$96 \%$

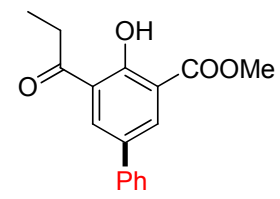

$80 \%$

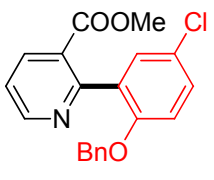

$87 \%$
图式 10 钴钛协同催化芳基金属试剂与卤代芳烃的偶联反应 Scheme $10 \mathrm{Co} / \mathrm{Ti}$ cooperatively catalyzed couplings of aryl metal reagents with aryl halides

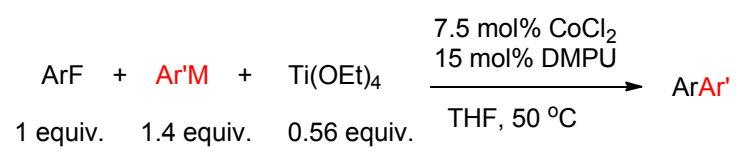

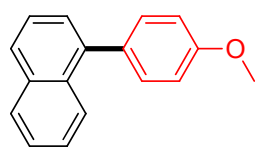

$77 \%$

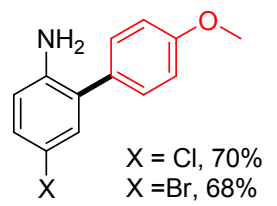

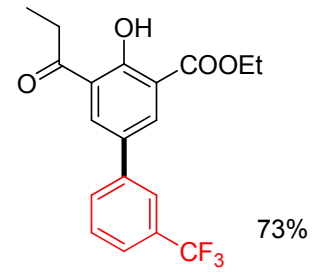

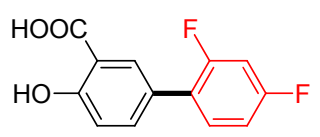

$85 \%$

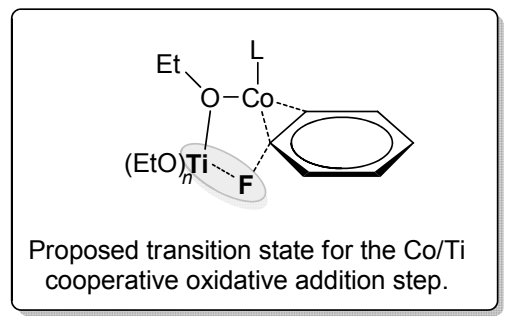

图式 11 钴钛协同催化芳基金属试剂与氟代芳烃的选择性偶 联反应

Scheme 11 Selective $\mathrm{Co} / \mathrm{Ti}$ Cooperatively catalyzed crosscouplings of aryl metal reagents with aryl fluorides

应的影响, 成功的实例较少 ${ }^{[37]}$. 最近, 我们课题组 ${ }^{[38]}$ 偶 
然发现, 向 $\mathrm{FeCl}_{3} / \mathrm{TMEDA} / \mathrm{Ti}(\mathrm{OEt})_{4}$ 加入酚盐, 有助于增 强铁钛协同效应, 避免脱卤和自身偶联, 成功实现了卤 代芳烃与芳基铁 ate 络合物的 $\mathrm{C}\left(\mathrm{sp}^{2}\right)-\mathrm{C}\left(\mathrm{sp}^{2}\right)$ 偶联(Eq. 4). 该反应多种碘代、溴代、氯代芳烃均适用, 并且具有优 异的官能团耐受性, 进一步拓展了有机钛试剂参与的偶 联反应范围。

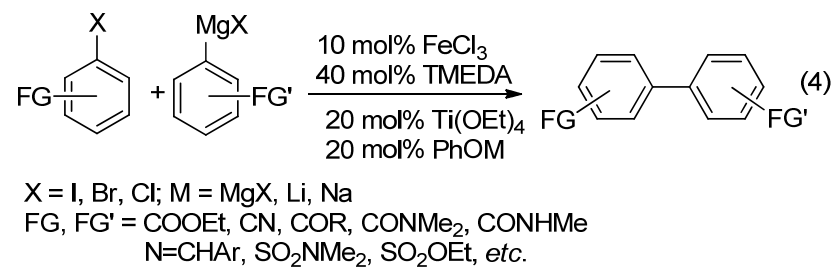

相对于金属试剂和卤代烃之间的偶联反应, 金属试 剂间的交叉氧化偶联反应更具挑战性. 传统的金属试剂 如锂试剂、格氏试剂等由于存在严重的自身偶联副反应, 交叉偶联收率很低. 2015 年, 我们课题组 ${ }^{[39]}$ 以 $\mathrm{FeCl}_{3}$ 为 催化剂, TMEDA 为配体, 首次实现了钛参与下含氮杂 环金属试剂与芳基金属试剂的高选择性氧化偶联反应. 该方法条件温和, 在 $\mathrm{O}_{2}$ 氧化下, 大多数含氮杂环金属试 剂于室温均能以高收率顺利实现交叉偶联，并可耐受酮 基、酯基、酰胺、氧基等敏感基团(Scheme 12). 值得注 意的是，两种金属试剂的加入顺序对反应结果有重要的 影响. 先将芳基金属试剂与 tbepc 反应生成具有 $\mathrm{C}$ - $\mathrm{Ti} \sigma$ 键的有机钛试剂, 再加入含氮杂环金属试剂, 所形成的 ate-络合物 $\operatorname{Ar}^{\mathrm{N}}\left[\mathrm{ArTi}(\mathrm{OR})_{3}\right] \mathrm{M}$ 能有效抑制芳基金属试剂 的自身偶联副反应. 反之, 由于含氮杂环钛试剂性质不 稳定, 反应主要得到联芳烃.
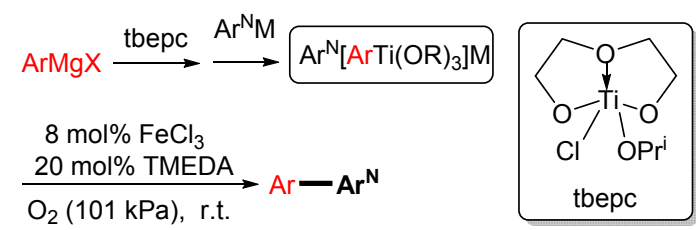

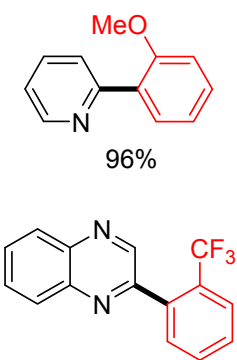

$87 \%$
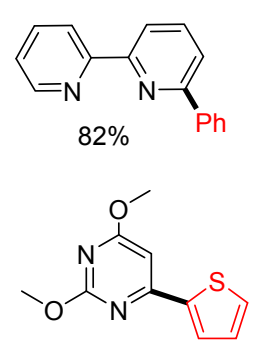

$82 \%$
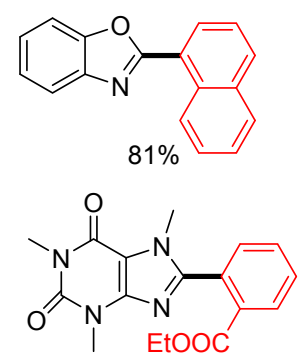

$80 \%$
图式 12 铁钛协同型 $\mathrm{Ar}^{\mathrm{N}}-\mathrm{M}$ 与 $\mathrm{Ar}-\mathrm{M}$ 的氧化偶联反应 Scheme $12 \mathrm{Fe} / \mathrm{Ti}$ cooperatively oxidative coupling between $\mathrm{Ar}^{\mathrm{N}}-\mathrm{M}$ and $\mathrm{Ar}-\mathrm{M}$

受此启发, 我们 ${ }^{[40]}$ 认为改变金属试剂与钛化合物
的加入顺序，可能使结构相似的两种金属试剂产生明显 的活性差异. 随之我们对钛参与下两种结构相近的芳基 金属试剂的氧化偶联反应进行了研究. 首先通过改变两 种芳基格氏试剂与 $\mathrm{ClTi}(\mathrm{OR})_{3}$ 的结合顺序，获得两种混 合型双芳基钛试剂 $\left(\mathrm{Ar}\left[\mathrm{Ar}{ }^{\prime} \mathrm{Ti}(\mathrm{OR})_{3}\right] \mathrm{MgX}\right.$ 和 $\mathrm{Ar}^{\prime}[\mathrm{ArTi}-$ $\left.\left.(\mathrm{OR})_{3}\right] \mathrm{MgX}\right)$ ，随后通过铁催化的氧化型交叉偶联反应 对其活性进行了比较(Scheme 13). 研究发现, 两种芳基 金属试剂中，活性较高者以 $\mathrm{C}$ - $\mathrm{Ti}$ 键、活性较低者以 ate 络合物形式与钛结合时，两者的反应活性将匹配，最大 程度地抑制自身偶联副产物的形成. 由上述两例反应可 见，钛的配体结构及加入顺序对于调控 ate-络合物反应 行为具有至关重要的作用.

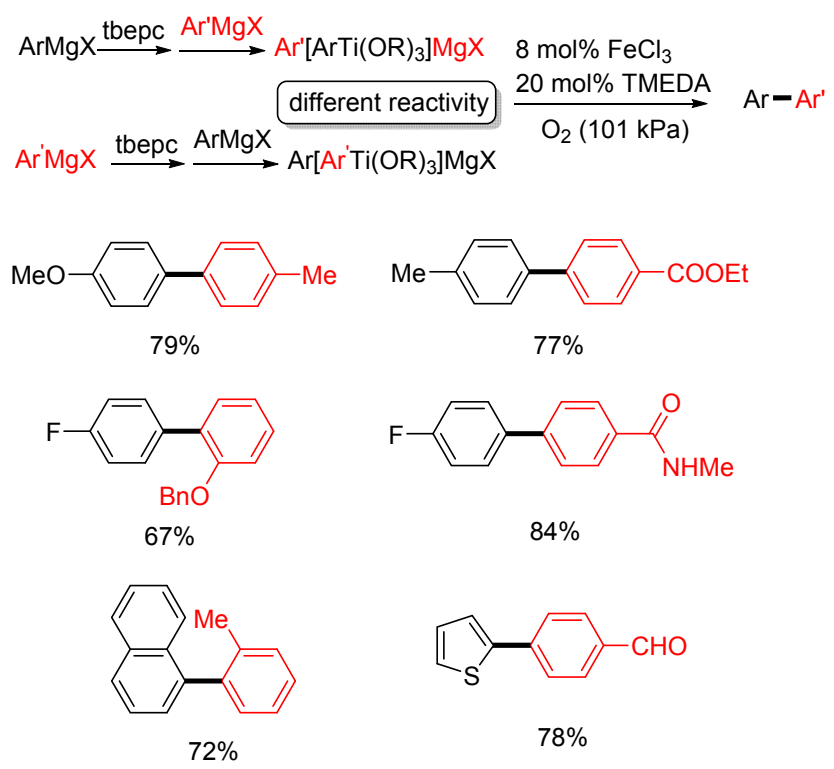

图式 13 铁钛协同型结构类似的 $\mathrm{Ar}-\mathrm{M}$ 间的氧化偶联反应 Scheme $13 \mathrm{Fe} / \mathrm{Ti}$ cooperatively oxidative coupling between $\mathrm{Ar}-\mathrm{M}$ with similar stuctures

同一时期，我们课题组 ${ }^{[41]}$ 还对钴催化的交叉氧化 偶联反应进行了研究, 发现普通的 $\mathrm{ClTi}(\mathrm{OEt})_{3}$ 同样能很 好地调控反应. 由于钴的催化活性更高, 因此只需要 1 $\mathrm{mol} \%$ 的 $\mathrm{CoCl}_{2}$, 在低温下即可实现芳基金属试剂高选择 性地氧化偶联反应(Scheme 14). 对底物适用范围的研 究表明, 该反应具有优异的化学选择性，不仅能耐受酯 基、亚胺基、卤素等官能团，结构相近的芳基金属试剂 也能获得高收率的交叉偶联产物. 另外, $\mathrm{ClTi}(\mathrm{OEt})_{3}$ 较 tbepc 更易制备，同时由于采用的催化剂量更少，配体 DMPU 毒性较小，因此反应操作简便、易于放大，对未 来工业化生产有利.

此外，近年来发展起来的过渡金属催化的脱羒偶联 使芳基羧酸化合物成为偶联反应的原料 ${ }^{[42]}$. 为此, 芳香 羧酸的烃基化反应一直是有机化学的研究热点之一. 


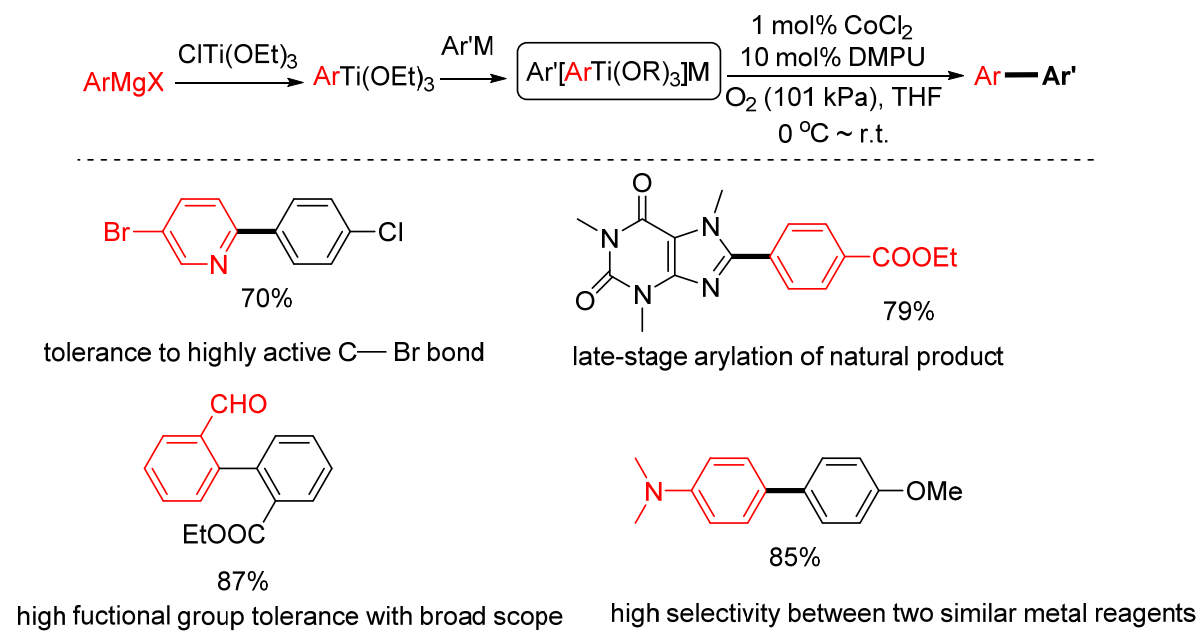

图式 14 钴钛协同型氧化偶联反应

Scheme $14 \mathrm{Co} / \mathrm{Ti}$ cooperatively oxidative coupling reactions.

2016 年, 我们课题组 ${ }^{[43]}$ 报道了钴钛协同型芳基羧酸金 属试剂与芳基金属试剂的氧化偶联反应，为芳基羧酸的 芳基化反应提供了一种条件温和，适用范围广的新方 法. 实验表明, 金属试剂与钛的结合方式对交叉偶联收 率有重要影响. 将芳基羧酸金属试剂、芳基金属试剂分 别与 0.5 equiv. 的 $\mathrm{Ti}(\mathrm{OEt})_{4}$ 络合形成 ate 络合物后, 在 7.5 $\mathrm{mol} \% \mathrm{CoCl}_{2} / 30 \mathrm{~mol} \% \mathrm{DMPU}$ 催化下, 以 $\mathrm{O}_{2}$ 为氧化剂, 两种金属试剂可顺利地实现交叉偶联反应. 与文献中芳 香羧酸局限于邻位芳基化反应 ${ }^{[37]}$ 相比, 我们的反应对 处于羧基邻、间、对位的芳基金属试剂均适用, 并表现 出较高的官能团耐受性. 利用上述反应, 进行了药物 Xenalepin、Tafamidis 以及心肌保护活性体的关键中间 体的一步法新合成(Scheme 15).

\section{3 总结与展望}

综上所述，最近发展的过渡金属催化下，有机钛试 剂与卤代烃、磺酸酯等进行交叉偶联反应, 以及钛试剂 参与氧化偶联反应等, 拓展了偶联反应的亲核试剂类 型，为高选择性偶联反应提供了一条新途径. 与此同时, 还有很多领域值得开拓: (1)有机钛试剂参与的偶联反应 类型有待拓展. 迄今为止, 过渡金属催化钛试剂的偶联 主要集中在 $\mathrm{C}-\mathrm{C}$ 键的构建. 近年来, 金属试剂参与的 $\mathrm{C}-\mathrm{H}$ 活化反应、碳一杂键的偶联反应以及不对称反应日 益受到人们的重视. 未来通过探索金属催化剂、有机钛 试剂、底物 $\mathrm{C}-\mathrm{H}$ 键的三元协同作用，建立高活性的催 化体系以及采用手性配体的钛试剂进行手性诱导，有望
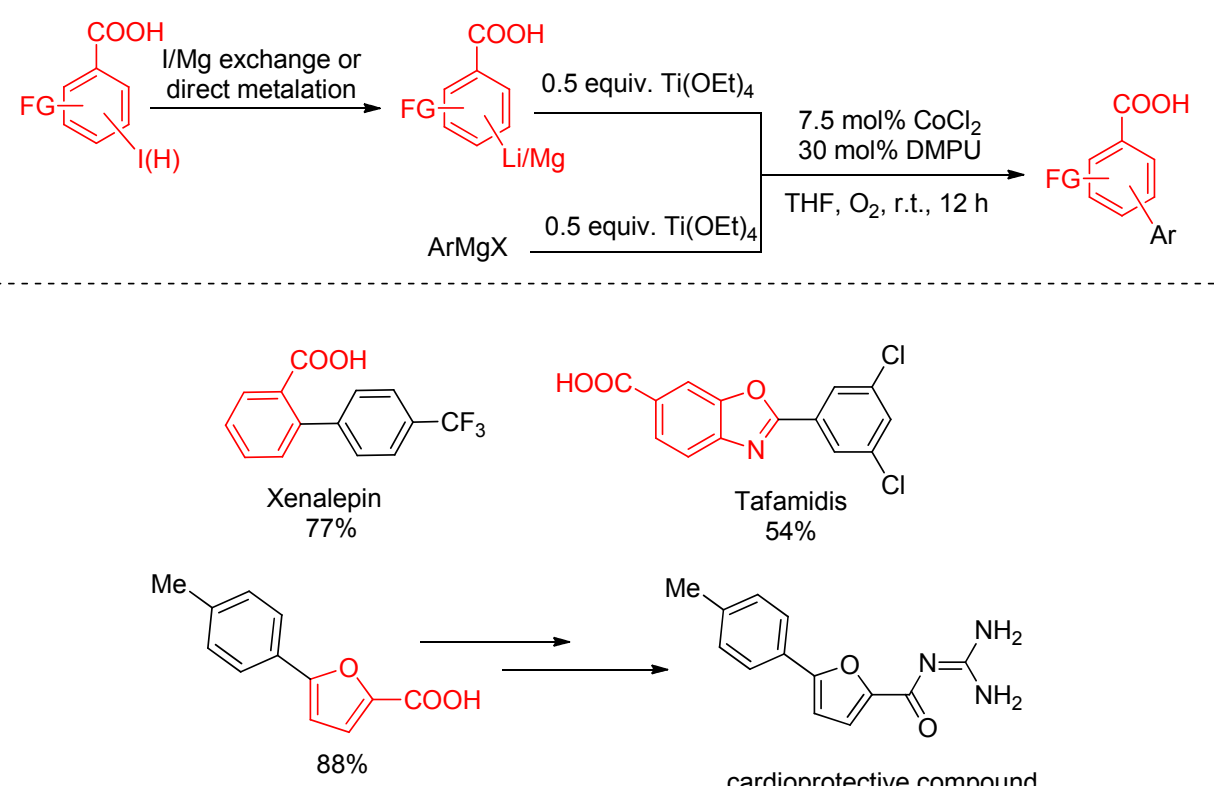

图式 15 钴钛协同型芳基羧酸金属试剂与芳基金属试剂的氧化偶联反应

Scheme $15 \mathrm{Co} / \mathrm{Ti}$ cooperatively oxidative coupling reactions of carboxylate and aryl metal reagents 
实现有机钛试剂在这几类反应中的应用. (2)新型钛试剂 在偶联反应中的应用有待发掘. 目前使用的有机钛试剂

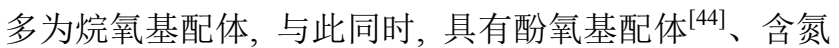
配体的钛试剂 ${ }^{[45]}$ 以及钛一烯、钛一炔络合物 ${ }^{[22]}$ 等相继被制 备出来, 并在其它类型反应中展现出独特的优势. 发掘 这些新型钛试剂的应用价值, 将进一步拓展偶联反应中 亲电试剂的类型. (3)反应机理尚需深入研究. 与传统金 属试剂相比, 有机钛试剂配位数大, 配体种类多, 在催 化循环中形成的中间体结构复杂. 目前只对最简单的 $\mathrm{RTi}\left(\mathrm{O}^{i} \mathrm{Pr}\right)_{3}$ 型钛试剂参与的偶联反应机理有所认识, 深 入研究反应机理对明确钛试剂反应活性与配体结构间 的关系、建立双金属协同催化机制具有重要的意义. 展 望未来, 我们相信, 过渡金属催化有机钛试剂的偶联反 应作为一个充满活力和希望的领域将进一步发展, 值得 我们做出不懈的努力.

\section{References}

[1] For Grignard reagent: (a) Tamao, K. J. Organomet. Chem. 2002, $653,23$.

(b) Knochel, P.; Dohle, W.; Gommermann, N.; Kneisel, F. F.; Kopp, F.; Korn, T.; Sapountzis, I.; Vu, V. A. Angew. Chem., Int. Ed. 2003, $42,4302$.

(c) Ha, H.; Baron, O.; Wanger, A. J.; Knochel, P. Chem. Lett. 2006, 35,2 .

[2] For Lithium reagent: (a) Barluenga, J.; Feunandez, A.; AlvarezRodrigo, L.; Rodriguez, F.; Fananas, F. J. Synlett 2005, 2513.

(b) Son, E. C.; Tsuji, H.; Saeki, T.; Tamao, K. Bull. Chem. Soc. Jpn. 2006, 79, 492

(c) He, P.; Dong, C. G.; Hu, Q. S. Tetrahedron Lett. 2008, 49, 1906.

[3] Knochel, P.; Singer, R. D. Chem. Rev. 1993. 93, 2117.

[4] Lipshutz, B. H. Acc. Chem. Res. 1997, 30, 277.

[5] (a) Miyaura, N.; Suzuki, A. Chem. Rev. 1995, 95, 2457

(b) Suzuki, A. Pure Appl. Chem. 1994, 66, 213.

[6] Espinet, P.; Echavarren, A. M. Angew. Chem., Int. Ed. 2004, 43, 4704.

[7] Weidmann, B.; Seebach, D. Angew. Chem., Int. Ed. Engl. 1983, 12, 31.

[8] (a) Reetz, M. T.; Steinbach, R.; Westermann, J.; Peter, R. Angew. Chem., Int. Ed. 1980, 92, 1044.

(b) Olivero, A. G.; Weidmann, B.; Seebach, D. Helv. Chim. Acta 1981, 64, 2485

(c) Widler, L.; Seebach, D. Helv. Chim. Acta 1982, 65, 1085.

(d) Widler, L.; Seebach, D. Helv. Chim. Acta 1982, 65, 1972.

[9] (a) Wu, S. Z.; Zhou, Y. K. Chin. J. Org. Chem. 1983, 3, 9 (in Chinese)

(吴绍祖，周耀坤，有机化学, 1983, 3, 9.)

(b) Chen, M. W. Chem. Reag. 1992, 14, 297 (in Chinese)

(陈美文，化学试剂, 1992, 14, 297.)

(c) Hughes, D. L. Top. Organomet. Chem. 2004, 6, 37.

(d) Kulinkovich, O. G.; Meijere, A. D. Chem. Rev. 2000, 100, 2789;

(e) Hayashi, T. Bull. Chem. Soc. Jpn. 2004, 77, 13.

(f) Yang, Z. S.; Li, Y. Chin. J. Org. Chem. 2005, 25, 1342 (in Chinese).

(杨忠顺，李英，有机化学, 2005, 25, 1342.)

(g) Kulinkovich, O. Comprehensive Organic Synthesis II, 2nd ed., Elsevier Ltd., Netherlands, 2014, 124.

[10] Weidmann, B.; Seebach, D. Helv. Chim. Acta 1980, 63, 2451

[11] Herman, D. F.; Nelson, W. K. J. Am. Chem. Soc. 1952, 74, 2693.

[12] Tolstikov, G. A.; Kasatkin, A. N. Izv. Akad. Nauk SSSR, Ser. Khim. 1984,2835
[13] Kasatkin, A. N.; Tolstikov, G. A.; Kulak, A. N. Izv. Akad. Nauk SSSR, Ser. Khim. 1986, 11, 2527.

[14] (a) Kasatkin, A. N.; Tolstikov, G. A.; Kulak, A. N. Izv. Akad. Nauk SSSR, Ser. Khim. 1987, 2, 391.

(b) Kasatkin, A. N.; Tolstikov, G. A.; Kulak, A. N. Izv. Akad. Nauk SSSR, Ser. Khim. 1988, 9, 2159.

[15] (a) Weber, B.; Seebach, D. Tetrahedron 1994, 50, 7473.

(b) Kim, Y. H.; Byun, I. S.; Choi, J. Y. Tetrahedron: Asymmetry 1995, 6, 1025.

(c) Zhou, S.; Chen, C.-R.; Gau, H.-M. Org. Lett. 2009, $12,48$.

(d) Wu, K.-H.; Zhou, S.; Chen, C.-A.; Yang, M.-C.; Chiang, R.-T.; Chen, C.-R.; Gau, H.-M. Chem. Comm. 2011, 4, 11668.

[16] Han, J. W.; Tokunaga, N.; Hayashi, T. Synlett 2002, 871

[17] Manolikakes, G.; Dastbaravardeh, N.; Knochel, P. Synlett 2007, 2077.

[18] Lee, H. W.; Lam, F. L.; So, C. M.; Lau, C. P.; Chan, A. S. C.; Kwong, F. Y. Angew. Chem., Int. Ed. 2009, 48, 7436.

[19] (a) Yang, H.-T.; Zhou, S.; Chang, F.-S.; Chen, C.-R.; Gau, H.-M. Organometallics 2009, 28, 5715.

(b) Chen, C.-R.; Zhou, S.; Biradar, D. B.; Gau, H.-M. Adv. Synth. Catal. 2010, 352, 1718.

[20] Chang, S.-T.; Li, Q.-H.; Chiang, R.-T.; Gau, H.-M. Tetrahedron 2012, 68, 3956.

[21] Li, Q.-H.; Liao, J.-W.; Huang, Y.-L.; Chiang, R.-T.; Gau, H.-M. Org. Biomol. Chem. 2014, 12, 7634.

[22] Sato, F.; Urabe, H.; Okamoto, S. Chem. Rev., 2000, 100, 2835.

[23] Harada, K.; Urabe, H.; Sato, F. Tetrahedron Lett. 1995, 36, 3203.

[24] Obora, Y.; Moriya, H.; Tokunaga, M.; Tsuji, Y. Chem. Commun. 2003, 2820.

[25] You, X.; Xie, X.; Sun, R. H.; Chen, H. Y.; Li, S; Liu, Y. H. Org. Chem. Front. 2014, 1, 940.

[26] Rassadin, V. A.; Nicolasb, E.; Six, Y. Chem. Commun. 2014, 50, 7666.

[27] Wittig, G. Angew. Chem. 1958, 70, 65.

[28] Jana, R.; Pathak, T. P.; Sigman, M. S. Chem. Rev. 2012, 111, 1417

[29] (a) Hatakeyama, T.; Hashimoto, T.; Kondo, Y.; Fujiwara, Y.; Seike, H.; Takaya, H.; Tamada, Y.; Ono, T.; Nakamura, M. J. Am. Chem. Soc. 2010, 132, 10674.

(b) Hashimoto, T.; Hatakeyama, T.; Nakamura, M. J. Org. Chem 2012, 77, 1168 .

(c) Hatakeyama, T.; Hashimoto, T.; Kathriarachchi, K. K. A. D. S.; Zenmyo, T.; Seike, H.; Nakamura, M. Angew. Chem., Int. Ed. 2012, $124,1$.

(d) Nakagawa, N.; Hatakeyama, T.; Nakamura, M. Chem. Lett. 2015, 44, 486 .

[30] (a) Muramatsu, Y.; Harada, T. Angew. Chem., Int. Ed. 2008, 47, 1088.

(b) Muramatsu, Y.; Harada, T. Chem.-Eur. J. 2008, 14, 10560.

(c) Nakagawa, Y.; Muramatsu, Y.; Harada, T. Eur. J. Org. Chem. 2010, 34, 6535 .

(d) Itakura, D.; Harada, T. Synlett 2011, 2875.

[31] Mikami, K.; Murase, T.; Itoh, Y. J. Am. Chem. Soc. 2007, 129, 11686.

[32] Arai, M.; Nakamura, E. J. Org. Chem. 1991, 56, 5489.

[33] (a) Li, Y.-X.; Xuan, Q.-Q.; Liu, L.; Wang, D.; Chen, Y.-J.; Li, C.-J. J. Am. Chem. Soc. 2013, 135, 12536.

(b) Semba, K.; Nakao, Y. J. Am. Chem. Soc. 2014, 136, 7567.

(c) Labre, F.; Gimbert, Y.; Bannwarth, P.; Olivero, S.; Duñach, E.; Chavant, P. Y. Org. Lett. 2014, 16, 2366.

(d) Seth, K.; Purohit, P.; Chakraborti, A. K. Org. Lett. 2014, 2334

[34] (a) Mulvey, R. E. Organometallics 2006, 25, 1060.

(b) Mulvey, R. E.; Mongin, F.; Uchiyama, M.; Kondo, Y. Angew. Chem., Int. Ed. 2007, 46, 3802.

[35] Zeng, J.; Liu, K.-M.; Duan, X.-F. Org. Lett. 2013, 15, 5342.

[36] Wei, J.; Liu, K.-M.; Duan, X.-F. J. Org. Chem. 2017, 82, 1291.

[37] (a) Bedford, R. B.; Hall, M. A.; Hodges, G. R.; Huwe, M.; Wilkinson, M. C. Chem. Commun. 2009, 42, 6430.

(b) O’Brien, H. M.; Manzotti, M.; Abrams, R. D.; Elorriaga, D.; 
Sparkes, H. A.; Davis, S. A.; Bedford, R. B. Nat. Catal. 2018, 1, 429.

[38] Zhang, R.; Zhao, Y.; Liu, K.-M.; Duan, X.-F. Org. Lett. 2018, 7942.

[39] Liu, K.-M.; Liao, L.-Y.; Duan, X.-F. Chem. Commun. 2015, 51, 1124.

[40] Liu, K.-M.; Wei, J.; Duan, X.-F. Chem. Commun. 2015, 51, 4655.

[41] Liao, L.-Y.; Liu, K.-M.; Duan, X.-F. J. Org. Chem. 2015, 80, 9856.

[42] (a) Goossen, L. J.; Paetzold, J.; Winkel, L. Synlett 2002, 1721.

(b) Goossen, L. J.; Deng, G.; Levy, L. M. Science 2006, 313, 662.

(c) Goossen, L. J.; Rodriguez, N.; Melzer, B. J. Am. Chem. Soc. 2007, 129, 4824.

(d) Zhou, J.; Peng, H.; Zhang, M.; Huang, S. J.; Wang, M.; Su, W.-P. Chem.-Eur. J. 2010, 16, 5876.

[43] Liu, K.-M.; Zhang, R.; Duan, X.-F. Org. Biomol. Chem. 2016, 14, 1593.
[44] (a) Lumbroso, A.; Abermil, N.; Breit, B. Chem. Sci. 2012, 3, 789.

(b) Iitsuka, T.; Schaal, P.; Hirano, K.; Satoh, T.; Bolm, C.; Miura, M. J. Org. Chem. 2013, 78, 7216.

(c) Zhang, M. L.; Zhang, H.-J.; Han, T. T.; Ruan, W. Q.; Wen, T.-B. J. Org. Chem. 2015, 80, 620

[45] (a) Vilardo, J. S.; Thorn, M. G.; Fanwick, P. E.; Rothwell, I. P. Chem. Commun. 1998, 22, 2425.

(b) Turner, L. E.; Thorn, M. G.; Swartz II, R. D.; Chesnut, R. W.; Fanwick, P. E.; Rothwell, I. P. Dalton Trans. 2003, 24, 4580.

[46] (a) Boyle, T. J.; Ottley, L. A. M.; Rodriguez, M. A.; Sewell, R. M.; Alam, T. M.; McIntyre, S. K. Inorg. Chem. 2008, 47, 10708.

(b) Muna, S.-D.; Kim, S.-H.; Lee, J.; Kim, H.-J.; Do, Y.-K.; Kim, Y.-J. Polyhedron 2010, 29, 379.

(c) Deivasagayam, D.; Peruch, F. Polymer 2011, 52, 4686

(Zhao, X.) 